Proceedings

\title{
Nature protection and local development: A methodological study implemented with reference to a natural park located in Sardinia (Italy)
}

\author{
Mara Ladu ${ }^{1 *}$, Martina Marras ${ }^{1 *}$ \\ 1 Department of Civil and Environmental Engineering and Architecture, University of Cagliari, Italy \\ * Correspondence: mara.ladu@hotmail.it (M.L.), martina.marras.mm@unica.it (M.M.).
}

Abstract: Italian legislation concerning the protection of natural heritage identifies the regional natural parks among the categories of the protected natural areas. Natural parks can include inner land areas, rivers, lakes, and coastal areas endowed with high natural and environmental values which, in many cases, are affected by high anthropic pressures. Therefore, planning should consider this problematic dichotomy and guarantee a balance between the conservation objectives and the development needs, according to the sustainability paradigm. Within this framework, the present study proposes a knowledge-based planning methodology that supports plan-making processes concerning natural parks, with the first aim to protect and enhance the Park-related opportunities and identity through the definition of place-based planning strategies.

Keywords: environmental planning; landscape planning; natural park; ecological balance

Citation: Ladu, M.; Marras, M.; Nature protection and local development: A methodological study implemented with reference to a natural park located in Sardinia (Italy). SUPTM 2022 conference proceedings sciforum-054125.

\section{Introduction}

According to the Italian Constitution and international agreements, Law no. 394/1991 (National law on natural protected areas) defines and classifies the protected natural areas [1-3] and identifies the regional natural parks among them. These can include inner land areas, rivers, lakes, and coastal areas endowed with high natural and environmental values. Within a park, such areas identify a homogeneous system based on natural characteristics and aspects of sites and on high-value views and landscapes, in respect of the cultural traditions of local communities. The law also introduces two main tools in order to guarantee and promote the conservation and enhancement of natural heritage, in a coordinated and balanced way: the spatial plan and the socio-economic program of the park. Focusing on the first, defining appropriate spatial planning tools for these areas is of outmost importance and it is the objective of this study. The spatial plan organizes land use and plan actions. It is an operational tool to which the spatial transformations, which have

Publisher's Note: UPCT and Sciforum stays neutral with regard to jurisdictional claims in published maps and institutional affiliations. effective consequences on the natural, social and economic environment, are addressed. Plans should identify and valorize the genius loci, that is the complex and peculiar identity of the local spatial contexts [4].

Furthermore, as regards natural parks, on the one hand, plans should grant protection and conservation of local natural values and of ecological balances; on the other hand, plans should also promote social and economic development [5], by implementing planning processes aimed at valorizing the local identity, according to the sustainable development paradigm. This problematic dichotomy deserves careful consideration because protected areas can border, or even include, urban settlements, as well as tourism hotspots, subject to high anthropic pressures [6]

Copyright: (C) 2022 by the authors. Submitted for possible open access publication under the terms and conditions of the Creative Commons Attribution (CC BY) license (https://creativecommons.org/license s/by/4.0/).

20 


\section{Area of study}

The Tepilora regional natural Park, located in central-eastern Sardinia (Italy), can be considered a relevant paragon for the issue at stake (Figure 1). As a matter of fact, the Park includes a relevant spatial context: it crosses four municipalities and different types of landscape. It develops from inland mountain areas to the coastal ones, it shows a rich microclimatic multiplicity, ecosystem diversity (in terms of habitat and species) and geological variety. This complexity can be considered a unique feature stressed by the recent establishment of a UNESCO Biosphere Reserve which includes the Tepilora natural Park and the municipal land of other municipalities located around the Park. In addition to the forest landscape, where the original natural features character prevails, the eastern part of the Park is characterized by an evident anthropization process. Here, the Park develops near the attractive town of Posada, includes the Rio Posada's environmental system [7], its alluvial-agricultural plain, the river's estuary connected with the coastal wetland zone and the adjacent beach, where a mainly seasonal tourism is developed in Summer. This area, called "Middle and low course of the Posada River", is one of the three landscaping areas which characterize the Park. The following methodology is developed working on its planning.

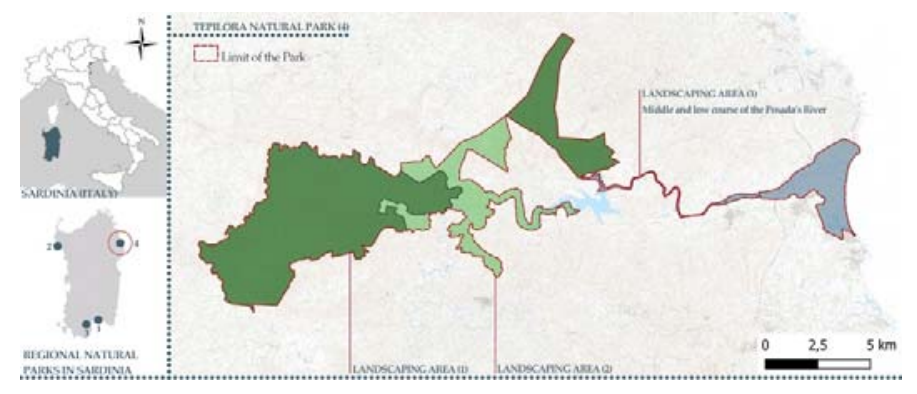

Figure 1. The Tepilora regional natural Park, located in Sardinia (Italy), and its landscaping areas.

\section{Methodology}

This study implements a knowledge-based planning methodology that supports plan-making processes concerning natural parks. The methodological approach is based on the following phases (Figure 2):

1. analysis of the spatial context of the Park;

2. identification of the governance framework and spatial planning tools in force;

3. characterization of the concept plan;

4. definition of a spatial taxonomy of homogeneous areas.

The first phase identifies the structural landscape's elements and a preliminary merging among similar landscaping areas. This phase includes reports on site visits, diachronic study of the orthophotos and analysis of the cognitive framework based on illustrative technical reports, analytical sheets, cartographic representation. Site visits are fundamental to investigate qualitative dynamics of the context and to start to hypothesize the consequences that the planning choices can have on a human scale. Diachronic study of the orthophotos shows the evolutions of the area of study and how and where trans-formation and anthropization processes engrave on it, on a landscape scale. A key role is represented by the illustrative technical reports and the analytical sheet of the Strategic Environmental Assessment, which in the case of the Tepilora regional natural Park is totally integrated with the planning process, and it gives a clear framework of territorial issues in site, it underlines core strength, weaknesses, opportunities and threats of each components determining the planning area and it contributes to define the objectives and actions of the Plan, on a territorial scale. As regards the cartographic representation some of the main aspects considered are the following: landcover, landscapes system (which unites aspects of flora, fauna and habitats) and geology. The second phase is about the 
identification of the governance framework and spatial planning tools in force. This aspect is important to evaluate the coherence between the local planning tools and the preliminary Plan. The third phase develops the characterization of the concept plan, consists in the attribution of an ad hoc protection level to homogeneous zones. According to art.12, Law no. 394/1991, four homogeneous zones are identified: zone A - full reserves; zone B general oriented reserves; zone $\mathrm{C}$ - conservation areas, zone $\mathrm{D}$ - areas of economic and social promotion. These are defined by the integration of the knowledge base preliminary zoning Plan (defined in phase 1) and the grade of transformation planned by the local municipal administrations (shown in phase 2). The last phase divides homogeneous zone more specifically in a spatial taxonomy of homogeneous areas, outlined as 'spatial reference units' (SRU), through the interpretation and systemization of available spatial analyses at a more detailed scale, concerning both conservation needs and development expectations.

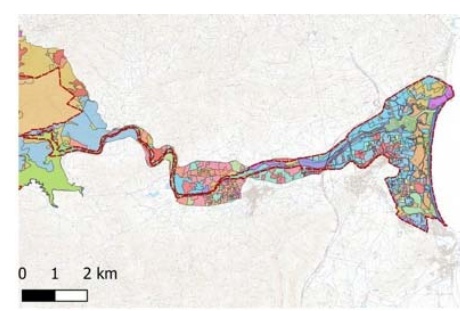

(a)

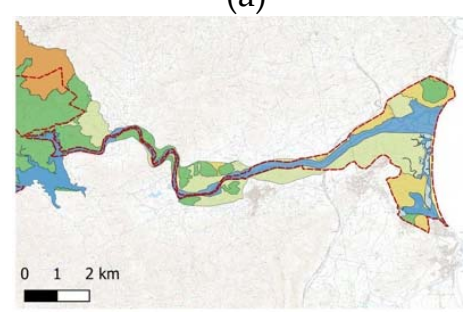

(c)

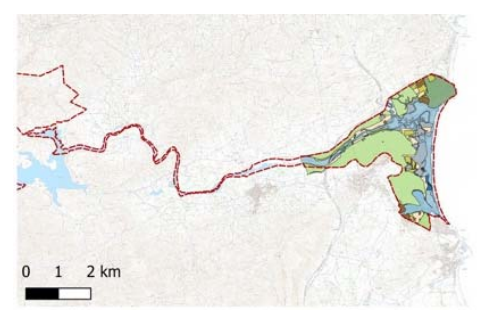

(b)

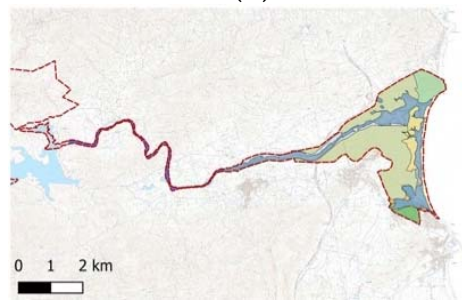

(d)

Figure 2. Some of the main aspects considered to define the zoning Plan: landcover (a), spatial planning tool of Posada (b), land-scape system (c), spatial reference units (SRU).

\section{Results}

According to art.12, Law no. 394/1991, three of the four homogeneous zones are identified in the "Middle and low course of the Posada River" as it follows:

- zone B: general oriented reserves;

- zone C: conservation areas;

- zone D: areas of economic and social promotion.

The surface of all the homogeneous zones covers approximately 955 ha of the Park in which the territorial Plan identifies 13 SRU as it follows:

- zone A: n. 0 SRU;

- zone B: n. 2 SRU, with a surface area of 217 ha ca;

- zone C: $n .7$ SRU, with a surface area of 271 ha ca;

- zone D: n. 4 SRU, with a surface area of 467 ha ca.

The $48,9 \%$ of the "Middle and low course of the Posada River" is represented by areas of economic and social promotion characterized by a high level of antropic transformation, both the general oriented reserves and the conservation areas occupy less than the $30 \%$ of the surface of the Macroarea, and no full reserves (zone A) are presented.

\section{Conclusions}

The knowledge-based planning methodology proposed makes it possible to develop a Plan which, starting from the comprehensive analysis of the territorial context and the definition of the planning strategy for the "Middle and low course of the Posada River", 
identifies a spatial taxonomy of homogeneous areas and introduces different degree of protection. In particular, the Plan assigns a high degree of protection to the water element consisting of a large part of the Posada River, understood as a general oriented reserve (zone B). Here, the scientific and educational use relating to the dissemination of knowledge of the Park is permitted, as well as the agricultural and traditional pastoral, forestry, tourist, recreational and cultural enjoyment. The latter can only take place with some restrictions in terms of the use of motor vehicles and the construction of new buildings and infrastructures. All the interventions that generate negative impacts on the environment and related ecosystems are not authorized. The conservation areas that perform the function of a buffer and filter zone between the water element and the rest of the plain (zone C) have a degree of protection aimed at ensuring greater use. Here, the construction of new buildings is permitted exclusively at improving the tourist accessibility of the Park. Finally, the Plan recognizes the consolidated role of areas of economic and social promotion to the rest of the plain where agricultural use prevails and to the urbanized areas of the Park (zone D). In these SRU, the Plan allows for a sustainable anthropic action aimed at enhancing the pre-existing economic activities, even through the construction of new buildings and services. At the same time, it introduces specific protection provisions for the most sensitive elements present in a widespread form, including small streams and woodland formations.

In conclusion, it can be said that the concept plan and the regulatory framework conserve the predominant landscape character of the Park. In this sense, the proposed methodology is effective in recognizing both expressed and unexpressed potentials of the spatial context, and it makes possible to protect and enhance the Park-related opportunities and identity. The methodology is readily exportable to other spatial contexts, at different spatial scales, where conservation and development pressures should be adequately balanced as regards areas characterized by relevant values of nature and natural resources.

Author Contributions: M.L. and M.M. collaboratively designed this study and jointly wrote Section 1, Section 2 and Section 4. Individual contributions are as follows: M.M. wrote Section 3; M.L. wrote Section 5. All authors have read and agreed to the published version of the manuscript.

Funding: This research received no external funding.

Acknowledgments: The study was implemented within the Research Program "Attivita di ricerca nell'ambito del Coordinamento scientifico nell'ambito della redazione, adozione ed approvazione del Piano del Parco così come definito dalla L.R. 21/2014 di istituzione del Parco naturale regionale di Tepilora e dalle ulteriori leggi nazionali e regionali vigenti in materia di parchi e aree protette" [Research activities in the context of the scientific coordination related to the definition, adoption and approval of the Plan of the Park under the provisions of regional Law no. 21/2014 concerning the establishment of the Natural Regional Park of Tepilora] implemented at the Department of Civil and Environmental Engineering and Architecture (DICAAR) of the University of Cagliari, Italy.

Conflicts of Interest: The authors declare no conflict of interest.

\section{References}

1. Carpita, F. Aree protette e tutela della biodiversità I parchi italiani nella cornice europea; Edizioni ETS: Pisa, 2016.

2. Ferrara, R.; Fracchia, F.; Rason, N. O.; Crosetti, A. Introduzione al diritto dell'ambiente; Gius. Laterza \& Figli Spa: Bari, 2018.

3. Di Lascio, F.; Giuseppe, P. La disciplina del patrimonio naturale e dei beni pubblici naturali in Italia. Revista Aragonesa de Administración Pública 2018, 17: 91-132.

4. Cassatella, C., Dall'Ara, E., Storti M. (eds), L'opportunità dell'innovazione; University press: Firenze, 2007.

5. Vinci, I. (ed), Piani e politiche territoriali in aree di parco. Cinque modelli di innovazione a confronto; Franco Angeli: Milano, 2007.

6. Selman, P. Planning at the landscape scale; Routledge: New York, 2006.

7. Ruiu, D. Ali sul fiume: vita nella foce del Rio Posada; Fabula, 2013. 